\title{
Identifying exceptions in a database of recognition failure studies from 1973 to 1992
}

\author{
LARS-GORAN NILSSON \\ University of Umeà, Umea, Sweden \\ and \\ JOHN M. GARDINER \\ City University, London, England
}

\begin{abstract}
This paper presents a database of all published studies based on the recognition failure paradigm, which involves the study of pairs of items followed by a recognition test of the second item of each pair and a recall test of the same target item with the first item of each pair provided as a context cue. The paper also identifies, on the basis of a quantitative analysis, exceptions to the recognition failure function encompassing most data in the database. The database includes reference information about each study and a short description of materials and the manipulations made in each of the 302 experimental conditions reported. The database also includes information about the total number of observations for each condition, the overall hit rate in free or forced choice recognition, the overall probability of recall, the observed probability of recognition given recall, the predicted probability of recognition given recall, the difference between observed and predicted values, and the critical ratio between these difference scores and their overall standard deviation.
\end{abstract}

In this article, we review all the published studies of the phenomenon of recognition failure of recallable words with two aims in mind. One goal is to provide a database of all existing data on this phenomenon with the specific purpose of examining the claim that these data conform with a mathematical function proposed by Tulving and Wiseman (1975). A second goal is to test the hypothesis that some exceptions, as previously discussed in the literature (e.g., Nilsson \& Gardiner, 1991), really do deviate markedly from this function. Exceptions to this function have never before been evaluated quantitatively with respect to all the recognition failure data available. A database is needed for this evaluation, along with a quantitative analysis that will identify large deviations in it.

This recognition failure function occurs in a particular situation, in which a recognition test for a particular set of target items is followed by a recall test for the same items, given item-specific contextual cues. In this situation, first clearly articulated by Tulving and Thomson (1973) and Watkins and Tulving (1975), the relation between recognition and recall of the same target items can be expressed by the probability of recognition given recall, or $p(\mathrm{Rn} \mid \mathrm{Rc})$. Tulving and Wiseman (1975) discovered that from all 40 of the known conditions that conformed with the recognition failure paradigm, there was a simple quadratic function relating the probability of recognition given recall to the overall probability of

This research was supported by a grant to L.-G.N. from the Swedish Council for Research in the Humanities and Social Sciences. Requests for reprints should be sent to L.-G. Nilsson, Department of Psychology, University of Umeå, S-901 87 Umeå, Sweden. recognition-the recognition hit rate. This relation is summarized by the following equation:

$$
p(\mathrm{Rn} \mid \mathrm{Rc})=p(\mathrm{Rn})+.5\left[p(\mathrm{Rn})-p(\mathrm{Rn})^{2}\right] .
$$

In a later summary, Flexser and Tulving (1978) found that all 89 conditions from published studies yielded observations close to values expected on the basis of Equation 1. More recently, however, some exceptions to this function have been observed. But these exceptions are principled, and they define the specific-as opposed to the situational-boundary conditions of the function (Gardiner, 1989; Gardiner \& Nilsson, 1990, 1993; Nilsson, Dinniwell, \& Tulving, 1987; Nilsson \& Gardiner, 1991; Nilsson, Law, \& Tulving, 1988).

We have proposed before that all exceptions to the function can be classified into one of two broad categories (Gardiner \& Nilsson, 1990; Nilsson \& Gardiner, 1991; Nilsson et al., 1988). In the first category, exceptions occur because the contextual cues are poorly related to their target words. In such circumstances, a nominally cued recall test becomes functionally like free recall, because the cues fail to provide any additional contextual information about the targets. So exceptions of this kind may be thought of as free-recall or encoding exceptions. If contextual items have not been encoded in relation to their targets, they will not, when presented as recall cues, be directed at the appropriate memory traces.

Exceptions in the second category occur because the information provided by contextual cues is largely inherent in the target words-that is, the recall cues are implicit in the recognition targets. In such circumstances, a nominally uncued recognition test becomes functionally 
like a cued recognition test. So exceptions of this kind may be thought of as cued-recognition or retrieval exceptions. The identification of exceptions falling into these two categories constitutes the major aim of this paper, in addition to the aim of making the database publicly available.

\section{THE DATABASE}

The database presented in the Appendix lists in order of publication (1) the specific experimental conditions included from each study, (2) the independent variables, (3) the type of recognition test (free vs. forced choice), (4) the overall recognition hit rate, (5) the overall probability of recall, (6) the observed probability of recognition given recall, (7) the predicted probability of recognition given recall, (8) the difference between observed and predicted values, and (9) the critical ratio between these difference scores and their overall standard deviation.

Following Tulving and Wiseman (1975) and Flexser and Tulving (1978), we have included in the database only experimental conditions in which uncued recognition preceded cued recall. In a number of studies, which are partially represented in the database, other sequences of combinations of tests have been used (e.g., Wallace, 1978). Such conditions are excluded from the database.

It should be noted that the very nature of the recognition failure function precludes the possibility of detecting large deviations from the function under certain circumstances. One such situation occurs when the level of recognition performance is quite high. In that circumstance, deviations may remain undetected because of ceiling effects (e.g., Nilsson \& Shaps, 1980). Another such situation occurs when the level of recall performance is quite high and exceeds the level of recognition. Tulving (personal communication, September 1977) showed that there are then mathematical constraints on $p(R n \mid R c)$, which increase as the level of recall increases, and more recently, Hintzman $(1991,1992)$ has argued that these mathematical constraints actually explain the functiona possibility that Tulving had rejected on empirical grounds (see Tulving \& Flexser, 1992).

Conversely, it is always possible that even large deviations from the function might reflect only experimental error, especially considering the large number of observations involved. This suggests that any purely quantitative definition of exceptions is likely to be unsatisfactory, and that an optimal definition requires both qualitative and quantitative criteria. Moreover, without the qualitative criteria, the definition of exceptions would be entirely circular because every large deviation would be called an exception, regardless of whether it could be categorized as an encoding or retrieval exception.

A further problem is that some of the exceptions that have been identified as such in the literature come from studies in which no attempt was made to evaluate the magnitude of the deviation statistically. This is particularly the case, of course, with some of the earlier studies (e.g., Bartling \& Thompson, 1977; Salzberg, 1975).

Given that the function summarizes the distribution of a set of observations - a set of observations that obviously entails an appreciable amount of natural variation-how is one to distinguish between deviations that reflect no more than natural variation and deviations that can be regarded as being abnormally large and falling outside the normal range?

We propose that the optimal solution to this problem is to analyze all the deviations from the function-that is, all differences between observed and predicted valuesby using critical ratio measures (Gardiner \& Nilsson, 1990; Nilsson \& Gardiner, 1991). The critical ratio (CR) is a measure of the ratio between single difference scores and the standard deviation for the whole set of difference scores. This approach has several distinct advantages over other possible ways in which the difference scores might be analyzed. Most obviously, it treats the entire set of scores as a single corpus of data. It does not involve carrying out a large number of individual pairwise comparisons. And the criterion value can be easily adjusted by, for example, adopting different confidence intervals. Furthermore, the lower the criterion is set, the less chance there is that difference scores that tend to be atypically large will be classified as being within the normal distribution of scores. These CR measures are listed in the final column of the Appendix. For confidence intervals of $95 \%$ and $90 \%$ the critical $C R$ values are 1.96 and 1.64 , respectively.

It should be emphasized that exceptions are conceived as a matter of degree. There is no clear-cut dichotomy between exceptions and nonexceptions, but rather a continuum between them. This continuity is encapsulated by our use of the CR measure and by comparing the $95 \%$ and $90 \%$ confidence levels.

These critical values can be used to see how well the deviations excluded on these grounds correspond with those that have been previously identified as exceptions in the literature. Given the nature of these quantitative criteria, one would of course expect a reasonable degree of correspondence. But nonetheless these criteria could reveal relatively large deviations that have not been identified as exceptions. Equally, they could indicate that some of the deviations previously identified as exceptions are not so atypically large when placed in the context of the entire corpus of data summarized in the Appendix.

The conditions in the database that exceed the $95 \%$ confidence level are: Conditions 129 and 130 (Begg, 1979); Condition 142 (Fisher, 1979); Conditions 160 and 164 (Gardiner \& Tulving, 1980); Condition 168 (Nilsson \& Shaps, 1980); Condition 201 (Muter, 1984); Conditions 249, 252, and 254 (Jones \& Gardiner, 1990); Conditions 269, 271, and 280 (Sandberg, 1990); Conditions 281, 284, and 285 (Bryant, 1991); and Conditions 297, 298, 301, and 302 (Ärlemalm \& Nilsson, 1992). At the $90 \%$ confidence level, the following exceptions would also be included: Condition 9 (Tulving, 1974); Condition 127 
(Begg, 1979); Condition 189 (Neely \& Payne, 1983); Condition 239 (Nilsson et al., 1988); and Condition 282 (Bryant, 1991). This analysis thus results in the inclusion at the $95 \%$ confidence level of a total of 20 deviations from the function summarized in Equation 1. Inclusion of deviations at the $90 \%$ confidence level adds another five conditions to the total set of exceptions in the present database. In the database, these 25 conditions are indicated by an asterisk.

Exceptions to the recognition failure function are defined as positive deviations, but the Appendix shows that there are also two large negative deviations from the function; that is, there are two deviations whose $\mathrm{CR}$ values exceed the $90 \%$ confidence interval that we have proposed as the quantitative criterion for defining exceptions. These are Conditions 103 and 133. It is possible that these negative deviations might reflect some unknown factor; but the conditions giving rise to them appear to have nothing in common, and so they most likely reflect experimental error. We therefore classify these deviations as aberrant observations that should also be excluded from the set of observations held to reflect the recognition failure function.

\section{Encoding Exceptions}

If the qualitative analysis in terms of two types of exceptions is correct, and if we then go through the experimental conditions that were identified as exceptions on the basis of the quantitative CR analysis, all of them should fit one or the other of the two categories. For ease of exposition, we review each of the categories in turn, beginning with free-recall or encoding exceptions. The major studies of exceptions of this kind are those of Begg (1979), Fisher (1979), Gardiner and Tulving (1980), Bryant (1991), and Ärlemalm and Nilsson (1992). The relevant conditions from these studies are characterized by weak encoding, brought about through "rote learning" instructions, poorly related cue-target materials, or both.

In Begg's (1979) Experiments 1 and 2, half the subjects were given instructions to encode unrelated word pairs by rote learning and half the subjects were given instructions to integrate the word pairs meaningfully. In the former conditions, it should have been difficult for subjects effectively to encode designated cue words in relation to their targets, and so these conditions should have given rise to exceptions. These are Conditions 120 and 127-132 in the Appendix, which shows that they did in general give rise to quite large positive deviations, though not in Conditions 128 and 132. Conditions 129 and 130 reached statistical significance by means of the $\mathrm{CR}$ analysis.

Similar results were obtained from similar conditions in Fisher's (1979) Experiment 2. These are Conditions 142 and 143 , in which subjects were given instructions for "repetition rehearsal" and there were low association values between the cues and their targets. Of these two conditions, only the former reached statistical reliability. With high association values between the cues and their targets, however, no large deviations were observed, even with repetition rehearsal, presumably because subjects then had little difficulty in effectively relating the cue-target pairs (Conditions 144 and 145). Similarly, with "meaningful rehearsal" instructions, the subjects were able to effectively relate cue-target pairs even when the association between them was low (Conditions 146 and 147), and no exceptions were observed.

Gardiner and Tulving (1980) used materials consisting of unrelated pairs of abstract words, or digit-word pairs, and compared "standard" encoding conditions with "special instructions" designed to train subjects effectively to relate these cue-target pairs. Under standard conditions of encoding (Conditions 159, 160,163, and 164) there were relatively large deviations from the function. Conditions 160 and 164 reached statistical significance by the critical ratio analysis. With special conditions of encoding (Conditions 161, 162,165, and 166), there was a much closer correspondence between observed and predicted values.

Sandberg (1990) used materials consisting of words or nonwords. The lists of pairs were so constructed that the two words of a pair could form either a word (e.g., foot-BALL) or a nonword (e.g., cup-PEAK); pairs of nonwords could also form a word (e.g., vasc-ULAR) or a nonword (e.g., rog-LUB). The word pairs were presented either once or five times. The prediction was that combinations of items forming nonwords would be more difficult to integrate, thus leading to a positive deviation from the function. It was also expected that such an exception would be more pronounced for one presentation than for five presentations. The predictions were confirmed, leading to large deviations for Conditions 269, 271, and 280, which were statistically significant by the $\mathrm{CR}$ analysis.

Bryant (1991) based one of his recognition failure experiments on the levels-of-processing paradigm (Craik \& Tulving, 1975). The results showed large statistically significant deviations from the function for the shallow structural or phonetic encoding conditions (Conditions 281 and 282) as measured by CR, but not for the deep semantic encoding condition (Condition 283). In a second experiment, Bryant manipulated the degree of association between the cue-target pairs. In line with the prediction, Bryant was able to demonstrate that the condition with no cue-target association (Condition 284) and that with a weak cue-target association (Condition 285) led to statistically reliable encoding exceptions as measured by CR.

Ärlemalm and Nilsson (1992) manipulated three variables: type of word pair, number of presentations, and type of instructions. Adjective-noun or noun-adjective pairs were presented once or five times after instructions for a subsequent recall test or for both a recognition and a recall test. The number of times a word pair was presented at study seems to have been the critical variable to produce large deviations from the function in this experiment. There were statistically significant exceptions, as measured by $\mathrm{CR}$, in all four cases of one presentation. For none of the four conditions with five presentations 
did the observed value differ significantly from the predicted value. It seems reasonable to interpret these data as showing that one presentation gives rise to a weaker cue-target association than do five presentations.

It is important to note that although free-recall or encoding exceptions are likely to occur when either the instructions or the materials (or both) make it difficult for subjects to relate cues to their targets, it does not follow that such conditions will invariably give rise to exceptions, because subjects will sometimes be able to overcome the limitations imposed by the instructions or by the materials. This probably explains why exceptions of this kind have also appeared in what seem to be more idiosyncratic circumstances-idiosyncratic, because they are isolated observations from different experiments, and because these experiments include other encoding conditions that, on the face of it, may not seem all that dissimilar.

Four such cases have been identified in the literature previously. They come from the studies by Salzberg (1975), Bartling and Thompson (1977), Neely and Payne (1983), and Nilsson et al. (1988).

Condition 57, from Salzberg's (1975) study, and Conditions 78 and 79, from Bartling and Thompson's (1977) study, appear to give rise to positive deviations and involve relatively abstract adjective cues. It seems reasonable to suppose that these deviations could be classified as encoding exceptions, because such cue-target pairs may have been difficult to integrate together. A similar interpretation can be made of the deviations shown in Condition 189, from Neely and Payne's (1983) study, and Condition 231, from Nilsson et al.'s (1988) study. Condition 189 involved nonfamous, rather than famous, names, so these names were therefore unrelated words. Condition 231 involved contextual phrases and geographical targets, which subjects had rated as being low in meaningfulness (e.g., Hat first made in Morocco), presumably because they had difficulty in relating the cues to the targets.

\section{Retrieval Exceptions}

We now review the second category of exceptions, cued-recognition or retrieval exceptions. Exceptions of this kind occur when subjects can implicitly retrieve much of the information provided by the recall cues from the targets in the recognition test. The major studies in relation to these exceptions are those of Muter (1984), Nilsson et al. (1987), Nilsson et al. (1988), and Jones and Gardiner (1990).

The first study in which deviations from the function would be expected on this basis is that of Tulving (1974). In this study, there were two conditions in which the recall cues were actually identical to their targets; that is, the recall cues were simply copies of the very same words. As it happens, however, only one of these two conditions showed a relatively large positive deviation reaching statistical significance (Condition 9, but not Condition 12).

The probable reasons for this have recently been clarified by Jones and Gardiner (1990). The hypothesis they tested was that the extent to which exceptions are observed with identical recall cues depends on the extent to which subjects adopt a guessing strategy in recall, on the basis of their knowing that some of the cues are copies of their targets. So, confronted by a recall cue that does not lead them to retrieve any specific contextual information, subjects may simply copy it. Jones and Gardiner therefore compared recognition and recall with identical cues when guessing was prohibited and when guessing was compelledthat is, when both recognition and recall were forced choice. Large positive deviations were observed when guessing was prohibited (Conditions 249, 252, and 254), but not when guessing was compelled (Conditions 257, 260 , and 262), thereby confirming the guessing strategy hypothesis and clarifying the conditions under which identical cues give rise to exceptions. All these three conditions $(249,252$, and 254$)$ reached statistical significance.

Deviations from the function have also been observed when the target words are category exemplars and the recall cues are the names of the categories. In these circumstances, when presented with the target words in the recognition test, subjects can retrieve the category names. Here too the information provided by the recall cues is implicit in the targets. Such materials were used in the studies by Nilsson and Shaps $(1980,1981)$. But, as can be seen in the Appendix, only in one condition from these studies is there a relatively large deviation from the function-Condition 168, which reached statistical reliability. Almost certainly, the reason for this is that in other relevant conditions from these studies the level of recognition performance was so high that deviations from the function cannot be detected. This conjecture is confirmed by the results of some unpublished experiments in which similar materials have been used with much longer retention intervals (Gardiner, Nilsson, \& Mäntylä, 1993). At these longer retention intervals, recognition performance was appreciably lower than in the studies done by Nilsson and Shaps $(1980,1981)$. And in each case, large deviations from the function were observed.

Evidence in support of this interpretation was provided by Nilsson et al. (1987). Lists were constructed in such a way that although some category instances were paired with category name cues, others were not, and so the category name cue was not predictable from the recognition target. Under these conditions (204-211 and 216-221), the data points were much as predicted, and no exceptions to recognition failure occurred.

The last exception of this kind was reported by Muter (1984). In Muter's experiment, there was no study list. Subjects were presented with surnames of famous people that were either unique names or common names (e.g., Ataturk, Cooper), and they were asked to indicate whether they recognized each name as being that of a famous person. On the subsequent recall test, the subjects were given a descriptive phrase for the person whose name was to be recalled (e.g., First president of the republic of Turkey, Kemal ; Author of the last of the 
Mohicans, James Fenimore ). Muter found that for the common names, recognition failure conformed closely to the function (Condition 200), but that for the unique names, there was almost complete dependency between recognition and recall (Condition 201) - an outcome that he interpreted as providing strong support for generaterecognize theory. As demonstrated by the critical ratio analysis, the deviation in Condition 201 reached statistical significance.

However, when subjects recognize ATATURK, for example, as being the name of a famous person, in so doing they are likely to retrieve information about him, including information about his being president of Turkey. So in this situation too, the information provided by the recall cues was largely implicit in the recognition targets. Evidence in support of this interpretation was obtained by Nilsson et al. (1988), who constructed a study list in which unique names of famous people were paired with apt but unexpected contextual phrases, phrases consisting of information unlikely to be retrievable from the names themselves (e.g., A scientist of uncertain ancestry: CHARLES DARWIN). Delayed tests of recognition of study list names, and then recall of the names given the contextual phrases as recall cues, showed that under these conditions, unique famous names did not give rise to any deviations from the function (Conditions 228, 229, and 230). Nilsson et al. also obtained similar results for unique geographical names (Conditions 232 and 233), except when, as has already been discussed, the subjects had given the materials low meaningfulness ratings.

The use of CR measures to define exceptions leaves open the possibility that there might be individual cases of positive deviations that are not large enough to meet the CR criterion but that reflect statistically significant differences between observed and predicted values by other tests such as binomial tests. There are only four such cases in the Appendix. Two of them, Conditions 192 and 196, were from the study by Neely and Payne (1983), and in each case there was significantly greater dependency between recognition and recall than expected from a binomial test. Word pairs were related in Condition 192 and unrelated in Condition 196, so the latter condition might indicate an encoding exception. Neely and Payne attributed the former difference to sampling error themselves. The other two conditions (245 and 246) were from the study done by Svensson and Nilsson (1989). In Condition 245 , the degree of dependency observed was lower than expected. However, the level of recognition performance was very high, so this observation might reflect a ceiling effect. In Condition 246 , significantly greater than expected dependency was observed for reasons that remain obscure. Any of these differences may, of course, reflect experimental error; or they may be due to some as yet undiscovered factor.

This completes our review of exceptions as they have been investigated and discussed in the literature. We conclude from this review of identified exceptions that all such exceptions do appear to be readily classifiable as belong- ing to one or the other of the two categories that we have defined. That is, whenever there is a large deviation from the recognition failure function, the reason is either that the cue-target pairs were weakly encoded or that much of the information provided by the recall cues can be implicitly retrieved from the targets in the recognition test. However, in concluding this, it is important, once again, to emphasize that there is no clear-cut dichotomy between exceptions and nonexceptions; their occurrence is a matter of degree.

\section{THEORIES}

Elsewhere, we have reviewed the two types of exceptionthe free-recall or the encoding exception and the cuedrecognition or the retrieval exception-in terms of existing memory theory (Nilsson \& Gardiner, 1991). Ratcliff and McKoon (1989) have also reviewed memory theories in relation to the recognition failure function. Since these reviews are already available, the aim here is merely to summarize the main conclusions; the interested reader is referred to these chapters for details. We considered four specific theories directly pertinent to the issue of the phenomenon of recognition failure of recallable words: vandal theory (Begg, 1979), dual mechanism theory (Jones, $1978,1983,1987)$, the retrieval independence model (Flexser \& Tulving, 1978), and the backward retrieval model (Rabinowitz, Mandler, \& Barsalou, 1977). It was concluded that none of these theories could account for both types of exception. The vandal theory and the dual mechanism theory can account for the encoding exceptions but not the retrieval exceptions. Conversely, the models of retrieval independence and backward retrieval can account for the retrieval exceptions but not for the encoding exceptions.

With respect to more general theories of memory Nilsson and Gardiner (1991) considered the ACT* model (Anderson, 1983), the SAM model (Gillund \& Shiffrin, 1984), MINERVA 2 (Hintzman, 1987), the matrix model (Humphreys, Bain, \& Pike, 1989), TODAM (Murdock, $1979,1982,1983$ ), and CHARM (Metcalfe, 1992). We concluded that the ACT* model and MINERVA 2 can account for encoding exceptions and that TODAM can be extended to accommodate encoding exceptions. The matrix model can account for retrieval exceptions but not for encoding exceptions. The SAM model, it was found, can account for the phenomenon of recognition failure of recallable words, but there is no mechanism that would account for either encoding or retrieval exceptions.

Metcalfe's (1992) CHARM model, finally, was found to be best equipped to account for the exceptions to the function. This is the only model that has so far been shown to account for both types of exception. The encoding exceptions can be accounted for without any restrictions, and the retrieval exceptions can be accounted for by assuming that relatively few features are encoded in the item vectors. 


\section{MATHEMATICAL CONSTRAINTS}

Hintzman $(1991,1992)$ has claimed that the TulvingWiseman function is an artefact due to mathematical constraints on the conditional probability of recognition given recall, particularly when the level of recall exceeds the level of recognition. In this circumstance, the value of $p(\mathrm{Rn} \mid \mathrm{Rc})$ cannot reach unity, and the severity of this constraint increases with higher levels of recall. Thus, the argument is that data points fall on the function or close to the function because they are mathematically compelled to do so. Hintzman (1991, 1992) also claimed that exceptions to the function occur when these constraints are absent.

Tulving and Flexser (1992) and Gardiner and Nilsson (1993) have recently argued against these claims of Hintzman's on empirical grounds. Tulving and Flexser based their analysis on the Flexser and Tulving (1978) database, whereas Gardiner and Nilsson based their analysis on a slightly earlier version of the database reported here. Both Tulving and Flexser (1992) and Gardiner and Nilsson (1991) rejected the mathematical artifact hypothesis because neither the function nor the exceptions can be related causally to these mathematical constraints. Data points conform to the function even when the mathematical constraints are absent (i.e., the level of recognition exceeds the level of recall) and exceptions do occur even when the mathematical constraints are present (i.e., the level of recall exceeds the level of recognition). Further evidence that there is no causal relation between these mathematical constraints and the function is discussed by Ärlemalm and Nilsson (1992).

However, such empirical refutations of Hintzman's mathematical model might not be conclusive-partly because the model is probabilistic, not deterministic, and therefore predicts only that exceptions are more likely to occur when the constraints are absent. It is also possible to regard Hintzman's model and our empirical account as being complementary. The model may or may not eventually prove to be falsifiable, on either formal or empirical grounds. But the model involves a complex set of assumptions that make it rather difficult to refute empirically. Our account is simple by comparison, and easier to test empirically, as our review here has shown.

\section{CONCLUSION}

The purpose of this article has been to provide a database of all existing data on the phenomenon of recognition failure of recallable words and to analyze this database to test the hypothesis that exceptions to the TulvingWiseman function really do deviate markedly from the function when all available data are taken into account. Critical ratio measures identify 25 abnormally large deviations. We have reviewed these deviations and shown on the basis of a qualitative analysis that they all fall into one of the two categories of exceptions described. These excep- tions occur either because recall cues are not functionally well related to the accompanying target words or because the recall cues are functionally equivalent to the target words. Thus, all large positive deviations from the function are principled, and the claim that the function is lawful is fully justified. Finally, we have also briefly considered Hintzman's (1991, 1992) mathematical model of the function and exceptions to it and the suggestion that at present this formal account and our empirical account can be regarded as being complementary. The database that we provide here can be used to further evaluate these-and other-controversial issues surrounding the phenomenon of recognition failure of recallable words.

\section{REFERENCES}

ANderson, J. R. (1983). The architecture of cognition. Cambridge, MA: Harvard University Press.

Ärlemalm, T., \& Nilsson, L.-G. (1992). Recognition failure of recallable words: Exception due to poor integration. Scandinavian Journal of Psychology, 33, 266-276.

Bartling, C. A., \& Thompson, C. P. (1977). Encoding specificity: Retrieval asymmetry in the recognition failure paradigm. Joumal of Experimental Psychology: Human Learning \& Memory, 3, 690-700.

BEGG, I. (1979). Trace loss and the recognition failure of unrecalled words. Memory \& Cognition, 7, 113-123.

Bowyer, P. A., \& HuMPhREYs, M. S. (1979). Effect of a recognition test on a subsequent recall test. Journal of Experimental Psychology: Human Learning \& Memory, 5, 348-359.

Bryant, D. J. (1991). Exceptions to recognition failure as a function of the encoded association between cue and target. Memory \& Cognition, 19, 210-219.

Craik, F. I. M., \& Tulving, E. (1975). Depth of processing and the retention of words in episodic memory. Journal of Experimental Psychology: General, 1, 268-294.

DoNNELLY, R. E. (1988). Priming effects in successive episodic tasks. Journal of Experimental Psychology: Learning, Memory, \& Cognition, 14, 256-265.

FISHER, R. P. (1979). Retrieval operations in cued recall and recognition. Memory \& Cognition, 7, 224-231.

Flexser, A. J., \& TUlviNG, E. (1978). Retrieval independence in recognition and recall. Psychological Review, 85, 153-171.

GARDINER, J. M. (1988). Recognition failures and free-recall failures: Implications for the relation between recall and recognition. Memory \& Cognition, 16, 446-451.

GARDINER, J. M. (1989). The Tulving-Wiseman law and exceptions to it. In A. F. Bennett \& K. M. McConkey (Eds.), Cognition in individual and social contexts (pp. 253-260). Amsterdam: North-Holland.

Gardiner, J. M., Kaminska, Z., Java, R. I., Clarke, E. F., \& MAYER, P. (1990). The Tulving-Wiseman law and the recognition of recallable music. Memory \& Cognition, 18, 632-637.

Gardiner, J. M., \& NiLsSON, L.-G. (1990). Relation between recognition and recall: The Tulving-Wiseman law (Umed Psychological Reports No. 205). Umeå, Sweden: University of Umeá, Department of Psychology.

GARDINER, J. M., \& NiLsson, L.-G. (1993). Mathematical constraints and the Tulving-Wiseman law: A rejoinder. Manuscript submitted for publication.

Gardiner, J. M., Nilsson, L.-G., \& Mäntylä, T. (1993). Recognition failure of categorized words: List length and retention interval. Manuscript in preparation.

GaRDINER, J. M., \& Tulving, E. (1980). Exceptions to recognition failure of recallable words. Joumal of Verbal Learning \& Verbal Behavior, 19, 194-209.

Gillund, G., \& Shiffrin, R. M. (1984). A retrieval model for both recognition and recall. Psychological Review, 91, 1-67. 
Hintzman, D. L. (1987). Recognition and recall in MINERVA 2: Anal ysis of the "recognition-failure" paradigm. In P. Morris (Ed.), Modelling cognition (pp. 215-229). London: Wiley.

Hintzman, D. L. (1991). Contingency analysis, hypotheses, and ar tefacts: Reply to Flexser and to Gardiner. Journal of Experimental Psychology: Learning, Memory, \& Cognition, 17, 341-345.

HintZMAN, D. L. (1992). Mathematical constraints and the "TulvingWiseman Law." Psychological Review, 99, 536-542.

HUMPHREYS, M. S., (1976). Relational information and the context ef fect in recognition memory. Memory \& Cognition, 4, 221-232.

HUMPHREYS, M. S. (1978). Item and relational information: A case for context independent retrieval. Journal of Verbal Learning \& Verbal Behavior, 17, 175-187.

Humphreys, M. S., Bain, J. D., \& Pike, R. (1989). Different ways to cue a coherent memory system: A theory for episodic, semantic, and procedural tasks. Psychological Review, 96, 208-233.

JoNES, G. V. (1978). Recognition failure and dual mechanisms in recall. Psychological Review, 85, 464-469.

Jones, G. V. (1983). Structure of the recall process. Philosophical Transactions of the Royal Society of London, 302B, 373-385.

JONES, G. V. (1987). Independence and exclusivity among psycholog ical processes: Implications for the structure of recall. Psychological Review, 94, 229-235.

Jones, G. V., \& GARDiner, J. M. (1990). Recognition failure when recognition targets and recall cues are identical. Bulletin of the Psychonomic Society, 28, 105-108.

Lieury, A. (1979). La memoire episodique est-elle emboitée dans la mémoire sèmantique? L'Année Psychologique, 79, 123-142.

MetCALFE, J. (1992). Recognition failure and the composite memory trace in CHARM. Psychological Review, 98, 529-553.

MURDOCK, B. B., JR. (1979). Convolution and correlation in perception and memory. In L.-G. Nilsson (Ed.), Perspectives on memory research (pp. 105-120). Hillsdale, NJ: Erlbaum.

MURDock, B. B., JR. (1982). A theory for the storage and retrieval of item and associative information. Psychological Review, 89, 609-662

MURDOCK, B. B., JR. (1983). A distributed memory model for serial order information. Psychological Review, 90, 316-338.

MUTER, P. (1978). Recognition failure of recallable words in semantic memory. Memory \& Cognition, 6, 9-12.

MUTER, P. (1984). Recognition and recall of words with a single meaning. Journal of Experimental Psychology: Learning, Memory, \& Cognition, 10, 198-202.

Neely, J. H., PAYNe, D. G. (1983). A direct comparison of recognition failure rates for recallable names in episodic and semantic memory tests. Memory \& Cognition, 11, 161-171.

Nilsson, L.-G., Dinniwell, M., \& Tulving, E. (1987). Recognition failure of categorized words. Memory \& Cognition, 15, 389-396.

Nilsson, L.-G., \& Gardiner, J. M. (1991). Memory theory and the boundary conditions of the Tulving-Wiseman law. In W. E. Hockley \& S. Lewandowsky (Eds.), Relating theory and data: Essays on human memory (pp. 57-74). Hillsdale, NJ: Erlbaum.

Nilsson, L.-G., LAW, J., \& Tulving, E. (1988). Recognition failure of recallable unique names: Evidence for an empirical law of memory and learning. Journal of Experimental Psychology: Learning, Memory, \& Cognition, 14, 266-277.

Nilsson, L.-G., \& ShaPS, L. P. (1980). A functional view of memory. In F. Klix \& J. Hoffmann (Eds.), Cognition and memory: Interdisciplinary research of human memory activities ( pp. 40-46). Berlin: Deutscher Verlag der Wissenschaften.

Nilsson, L.-G., \& ShaPS, L. P. (1981). A reconstructive processing interpretation of the recognition failure phenomenon. Acta Psychologica, 47, 25-37.

Payne, D. G., \& Neely, J. H. (1983). Recognition failure of recallable famous names in a hybrid semantic-episodic memory task. Bulletin of the Psychonomic Society, 21, 85-88.

Postman, L. (1975). Tests of the generality of the principle of encoding specificity. Memory \& Cognition, 3, 663-672.
RABINOWITZ, J. C. (1984). Aging and recognition failure. Journal of Gerontology. 39, 65-71.

Rabinowitz. J. C.. Mandler, G.. \& Barsalou, L. W. (1977). Recognition failure: Another case of retrieval failure. Journal of Verbal Learning \& Verbal Behavior, 16, 639-663.

RAtcuff, R., McKoon, G. (1989). Memory models, text-processing. and cue-dependent retrieval. In H. L. Roediger III \& F. I. M. Craik (Eds.), Varieties of memory and consciousness ( pp. 73-92). Hillsdale, NJ: Erlbaum.

Reder, L. M., Anderson, J. R., \& Bjork, R. A. (1974). A semantic interpretation of encoding specificity. Journal of Experimental Psychology, 102, 648-656

Rönngerg, J., Lyxell, B., Samuelsson, S., Erngrund, K., a NilsSON, L.-G. (1991). Recognition failure of prose-embedded words. Journal of Experimental Psychology: Leaming. Memory, \& Cognition, 17, 288-301

SAlZBERG, P. M. (1975). On the generality of encoding specificity. Journal of Experimental Psychology: Human Learning \& Memory, 2. 586-596.

SANDBERG, K. (1988). Recognition failure of recallable words: Free and cued recall compared. Scandinavian Journal of Psychology, 29. 129-136.

SANDBERG, K. (1990). Integration and cue overlap in recognition failure of recallable words. Scandinavian Joumal of Psychology, 31, 302-314.

Shaps, L. P., Nilsson, L.-G. (1980). Encoding and retrieval operations in relation to age. Developmental Psychology, 16, 636-643.

SVEnsson, T., NiLsson, L. -G. (1989). The relationship between rec ognition and cued recall in memory of enacted and nonenacted information. Psychological Research, 51, 194-200.

TAIJKA, H. (1977). Features of recognition tasks in encoding specificity: Types of frequency associates in extralist cue words types of recognition tasks. Psychologia, 20, 151-158.

TAIJKA, H. (1978a). Features of recognition tasks in encoding specificity: The function of context in recognition tasks. Japanese Psychological Research, 20, 93-100.

TAIJKA, H. (1978b). Features of recognition tasks in encoding specificity: The function of free associates tasks and non-verbal tasks. Japanese Journal of Psychology, 48, 344-347.

TAIJKA, H. (1979). Memory processes in recall and recognition. Psychologia, 22, 146-154.

TulviNG, E. (1974). Recall and recognition of semantically encoded words. Journal of Experimental Psychology, 102, 778-787.

Tulving, E., F FEXSER, A. J. (1992). On the nature of the TulvingWiseman function. Psychological Review, 99, 543-546.

Tulving, E., Thomson, D. M. (1973). Encoding specificity and retrieval processes in episodic memory. Psychological Review, 80, 352-373.

Tulving, E., \& Watkins, O. C. (1977). Recognition failure of words with a single meaning. Memory \& Cognition, 5, 513-522.

Tulving, E., \& Wiseman, S. (1975). Relation between recognition and recognition failure of recallable words. Bulletin of the Psychonomic Society, 6, 79-82.

VINING, S. K., \& NELSON, T. O. (1979). Some constraints on the generality and interpretation of the recognition failure of recallable words. American Journal of Psychology, 92, 257-276.

WALLACE, W. P. (1978). Recognition failure of recallable words and recognizable words. Journal of Experimental Psychology: Human Leaming \& Memory, 4, 441-452.

Watkins, M. J., \& Tulving, E. (1975). Episodic memory: When recognition fails. Journal of Experimental Psychology: General, 104, 5-29.

Wiseman, S., \& Tulving, E. (1975). A test of confusion theory of encoding specificity. Journal of Verbal Learning \& Verbal Behavior. 14, 370-381.

Wiseman, S., \& TUlving, E. (1976). Encoding specificity: Relation between recall superiority and recognition failure. Journal of Experimental Psychology: Human Learning \& Memory, 2, 349-361. 


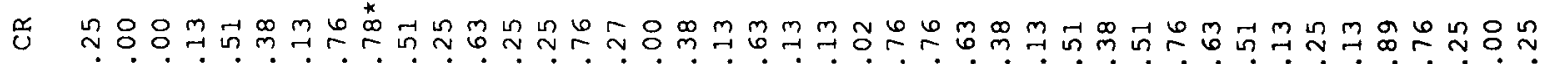

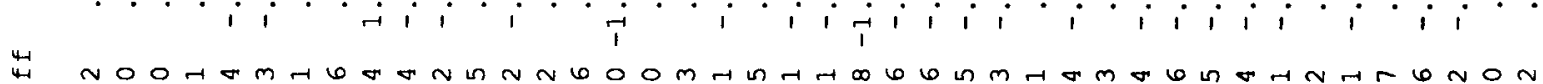

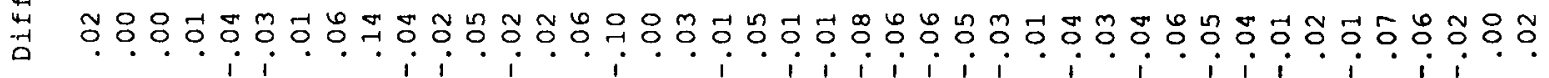
总 ํํ․

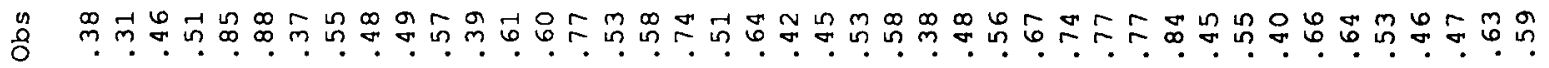

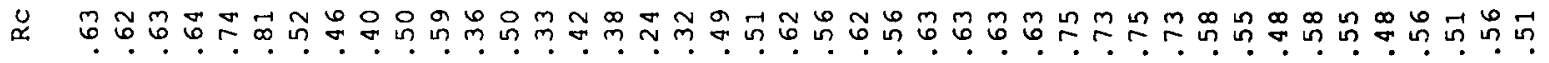

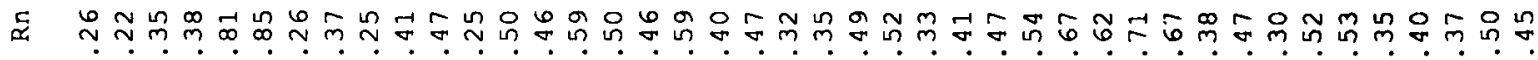

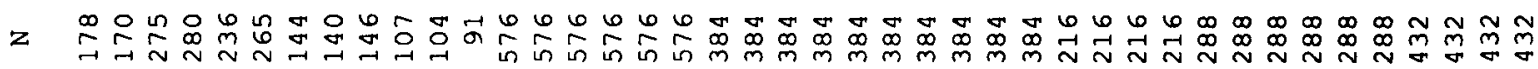

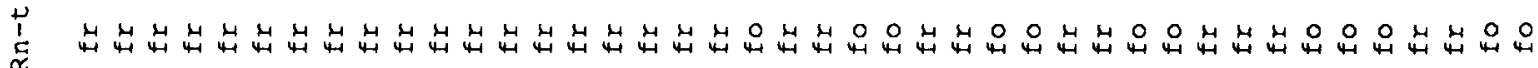

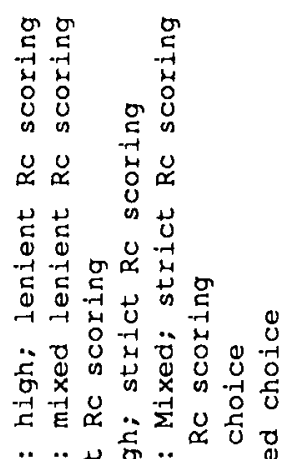

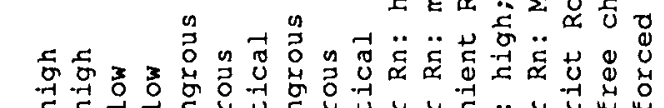

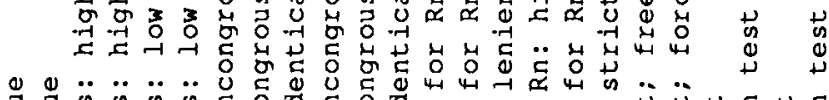
J

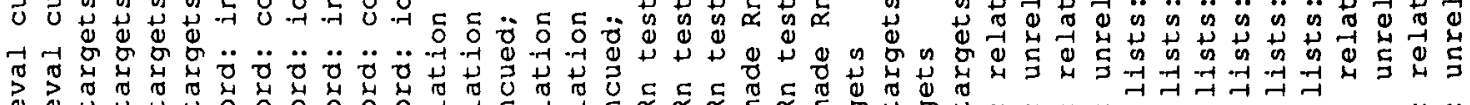

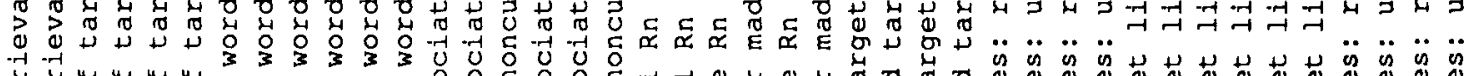

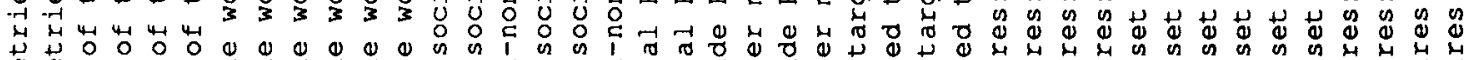

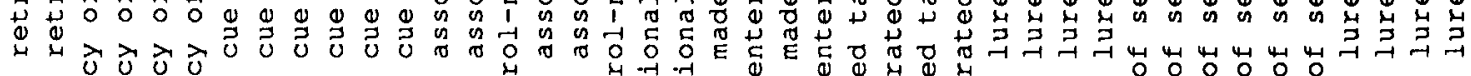

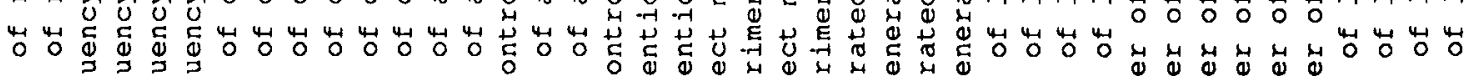
@ @

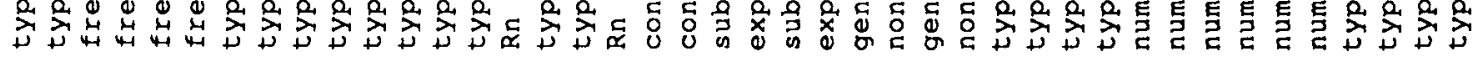
足 西

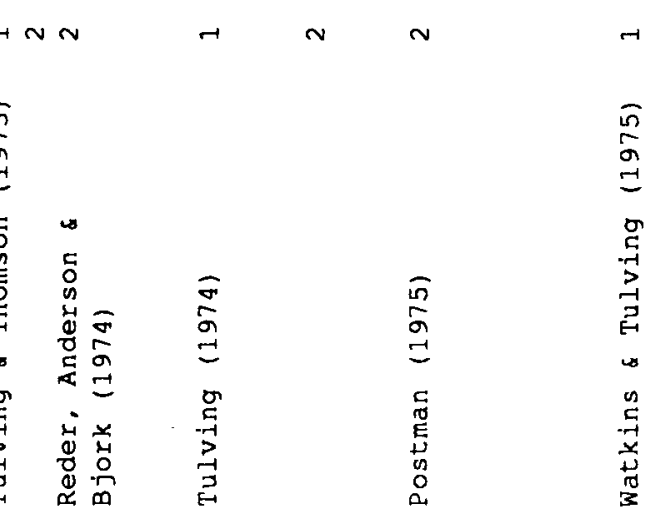

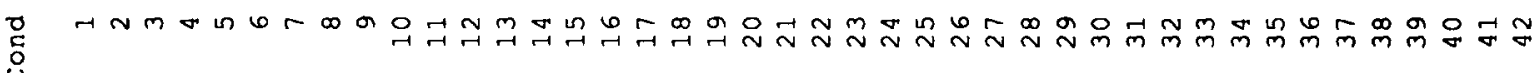




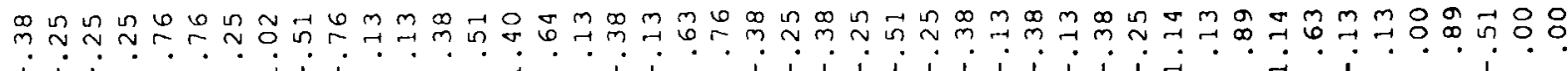
$\begin{array}{ll}1 & 1 \\ m & \end{array}$

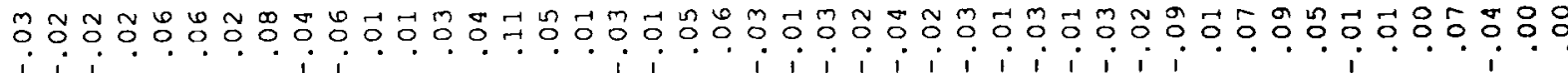

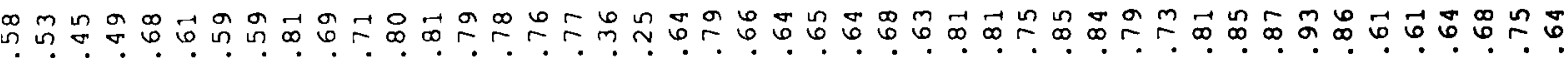

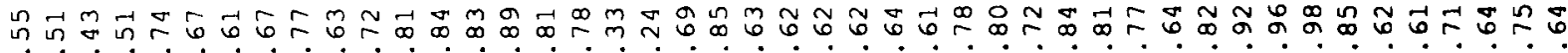
бํํㅇำ

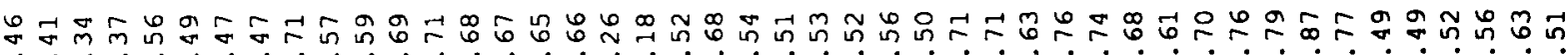

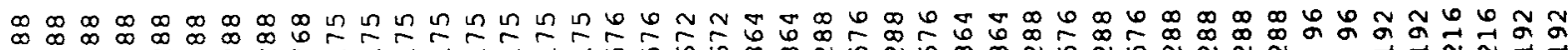

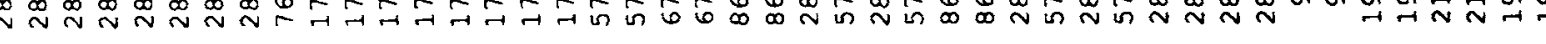

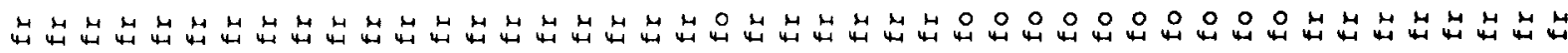

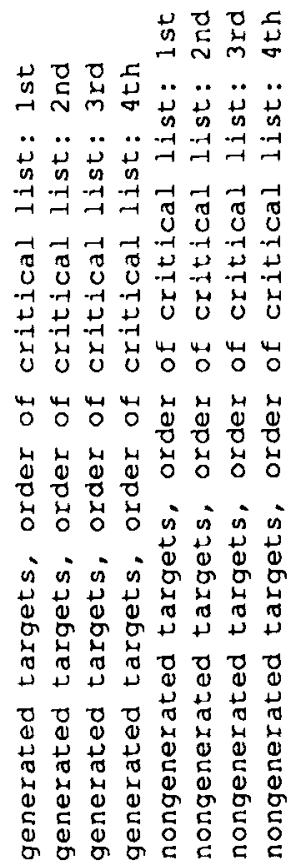

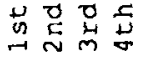

$-$

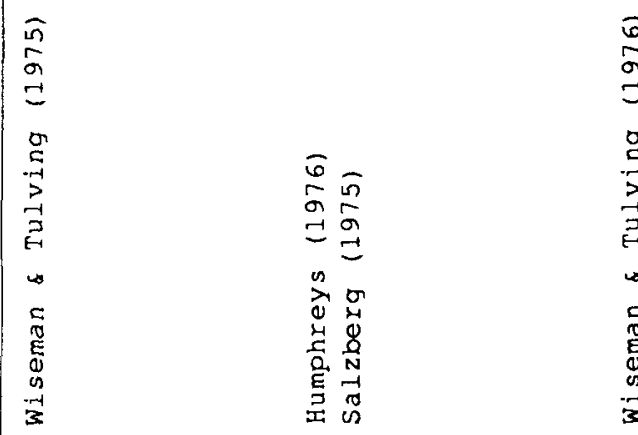

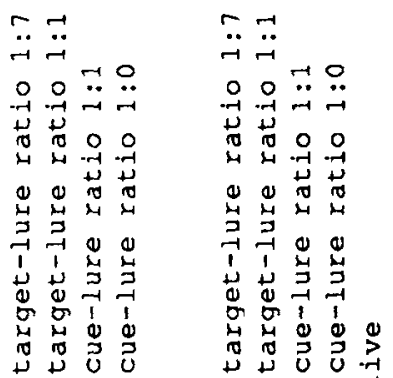

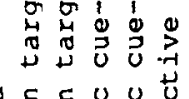

证

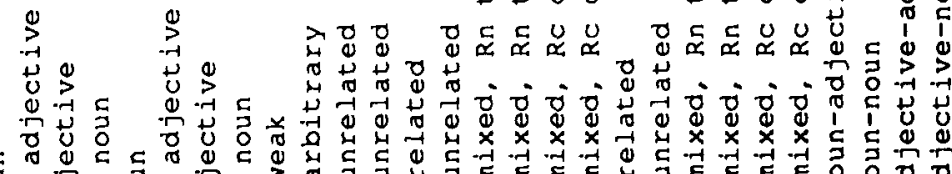
ᄃ

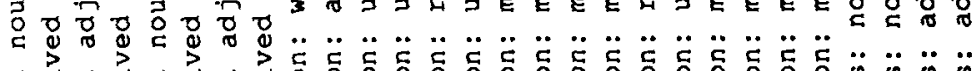

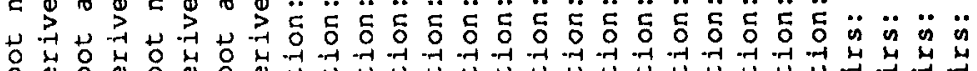

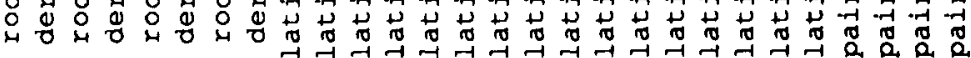

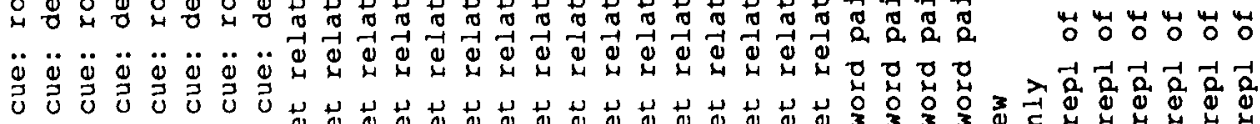
0 0 0

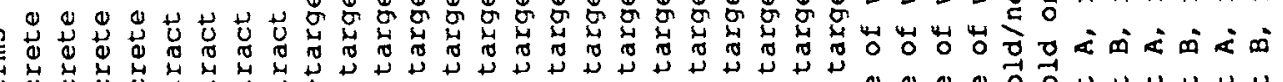

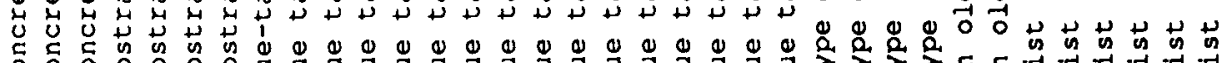

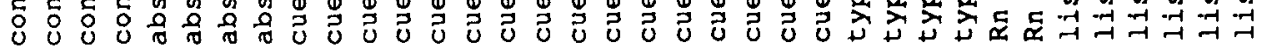

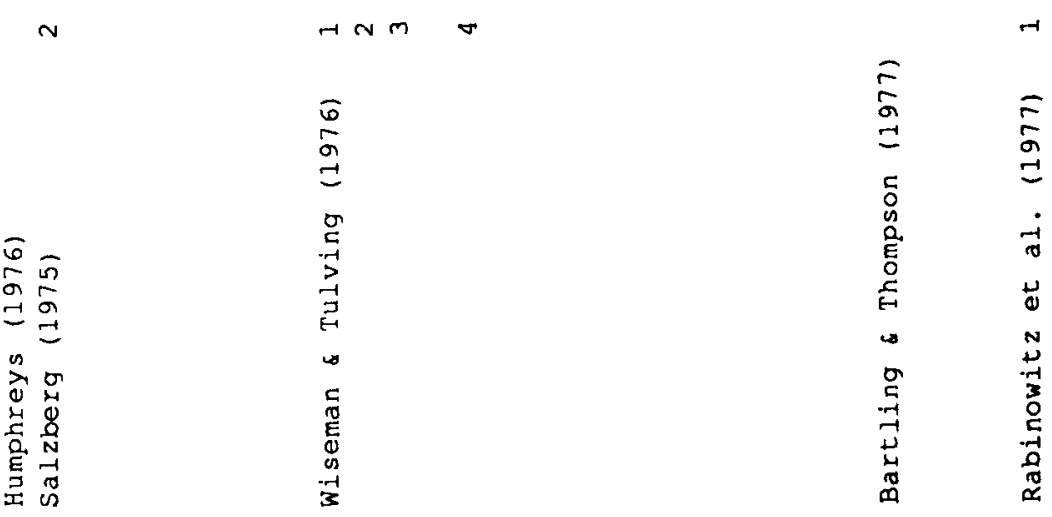

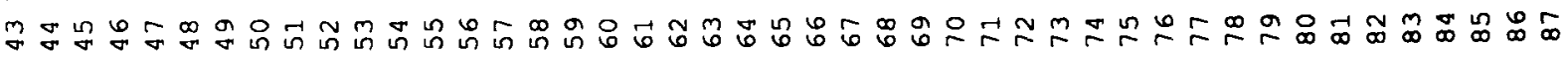




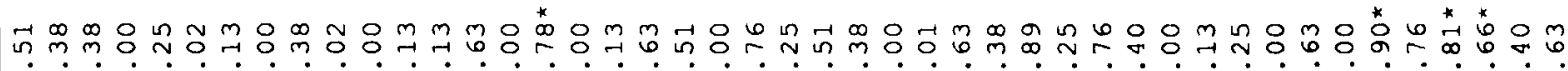

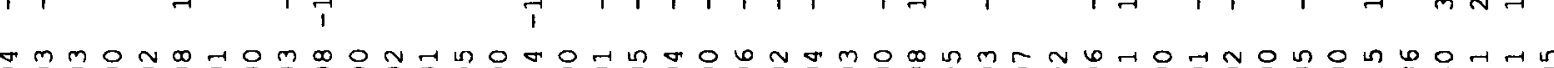

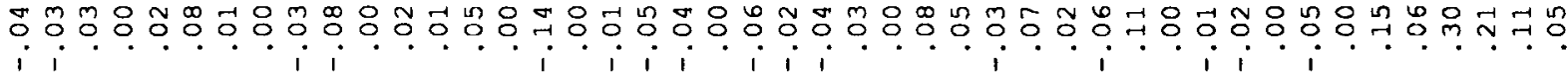

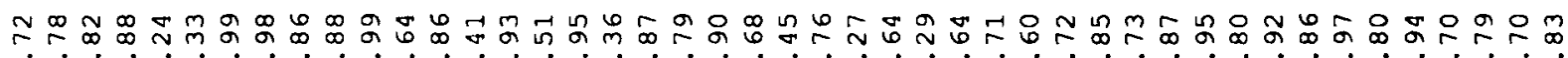

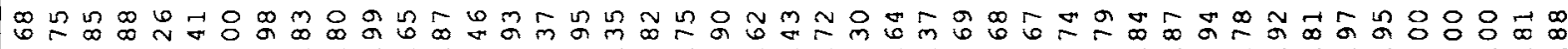

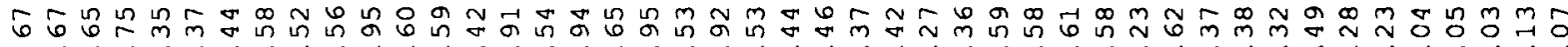

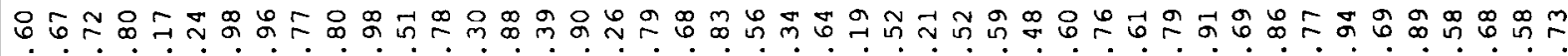

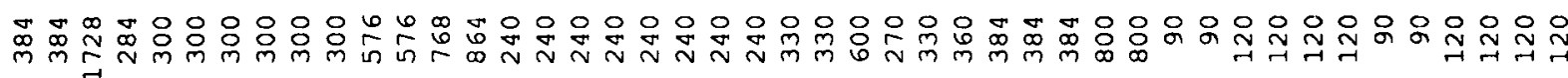

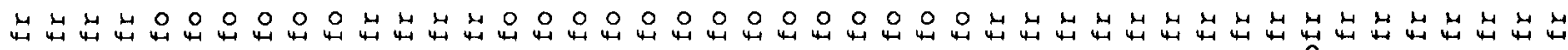

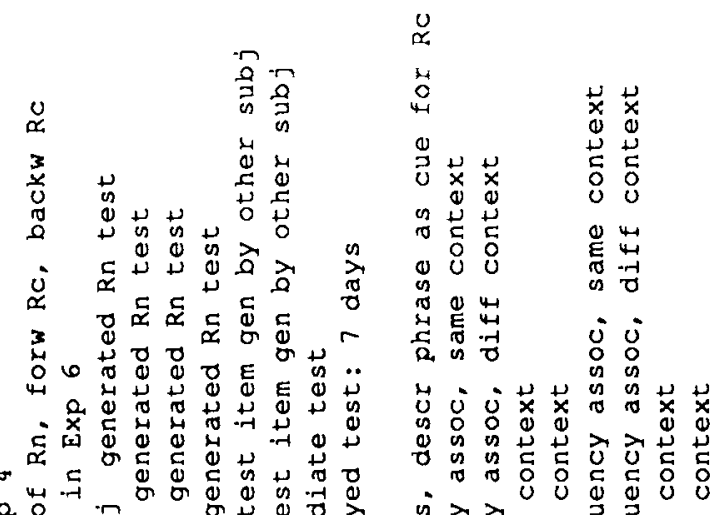

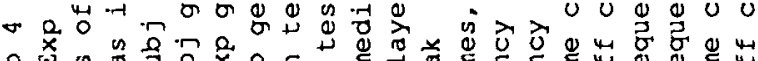

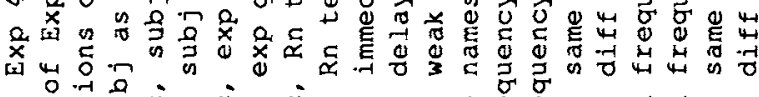

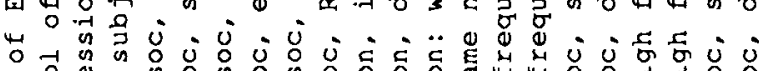
卉至

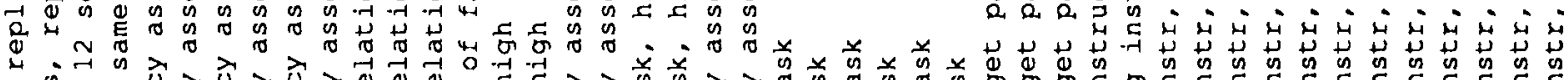

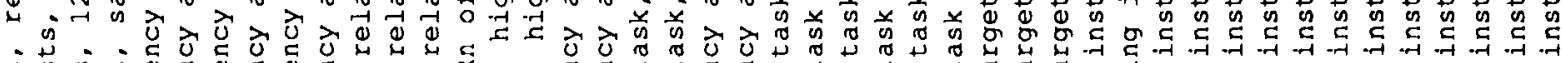

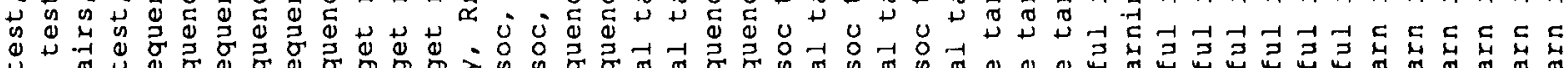

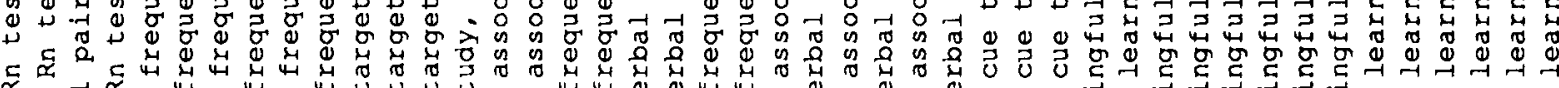

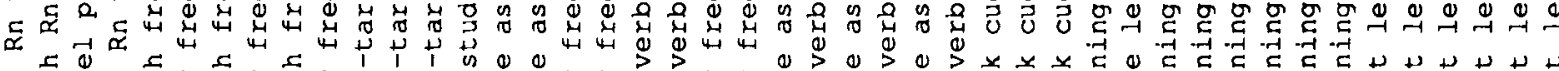

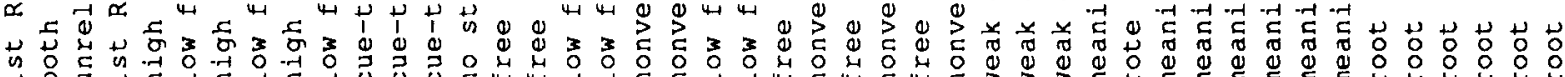

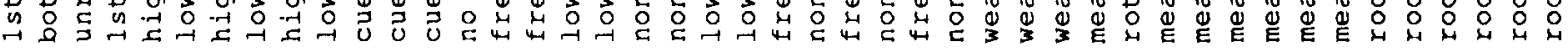

in $6 \mathrm{r}$

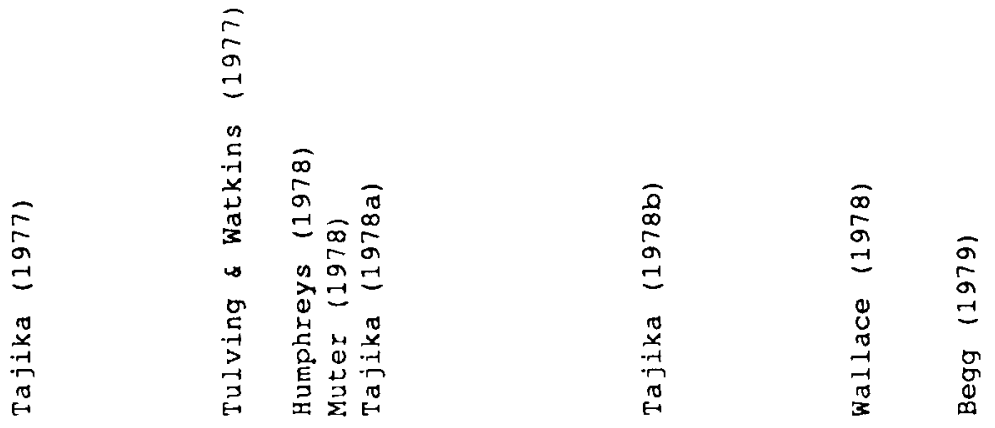

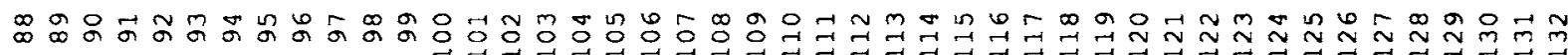




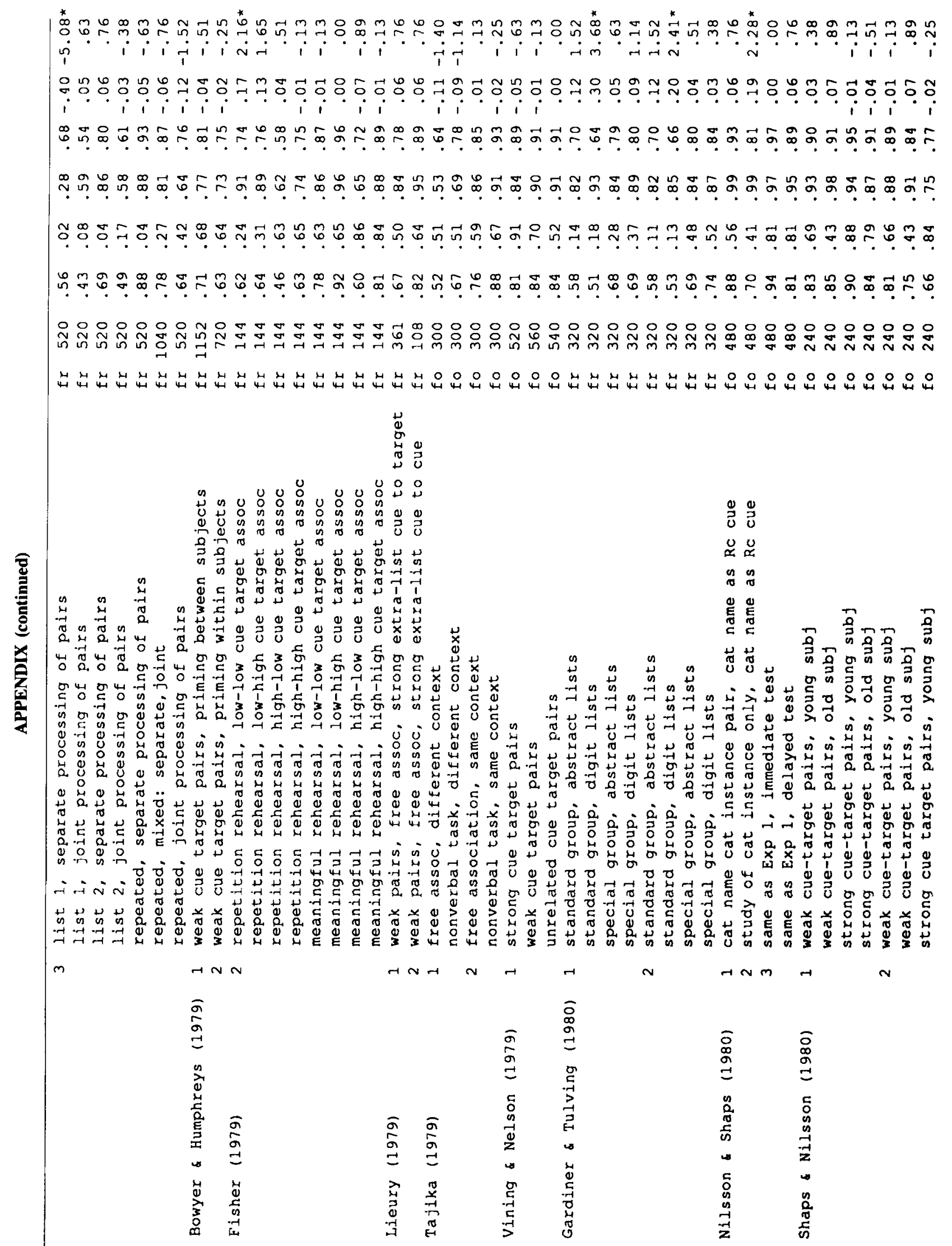

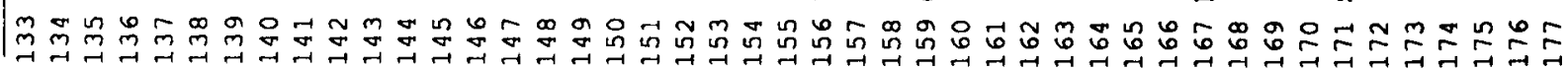




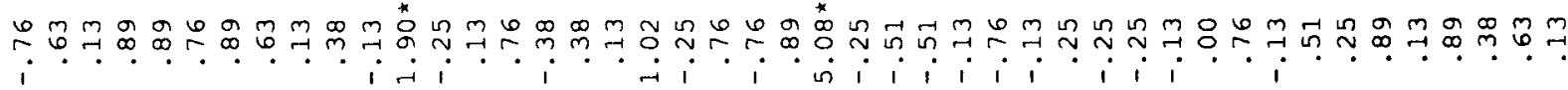

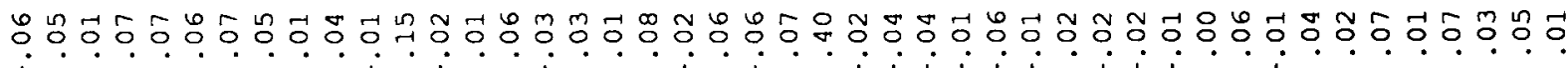

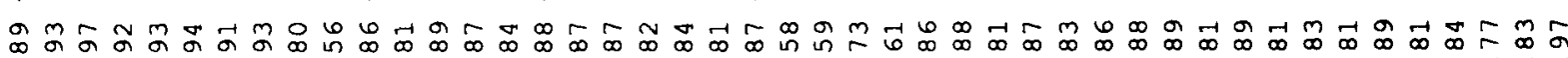
గొ m

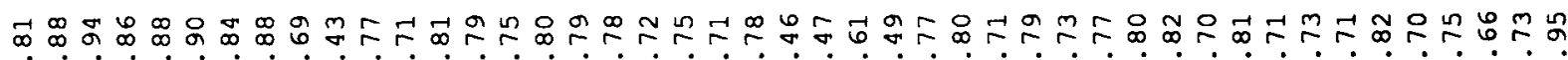

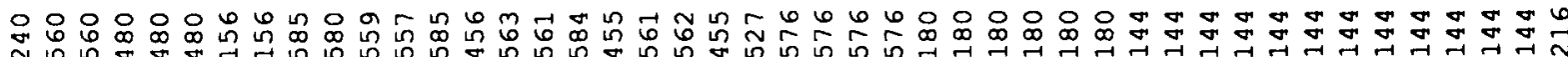

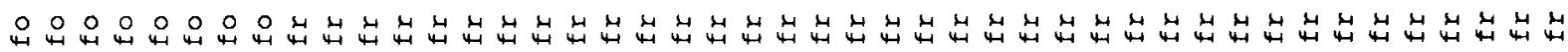

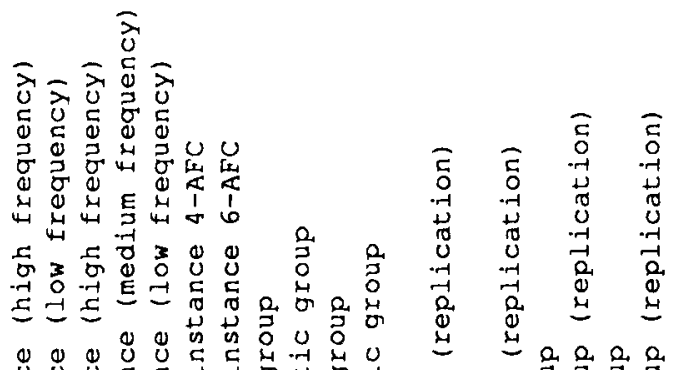

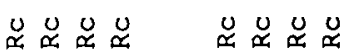

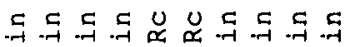

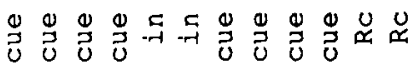
$\mathscr{E}$

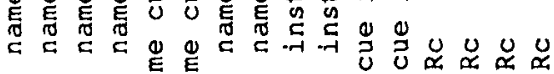

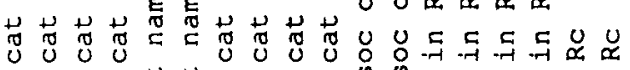

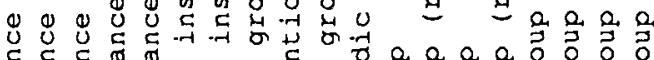

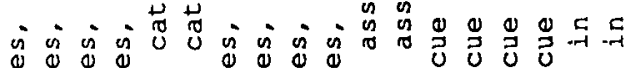
때유.

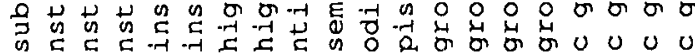

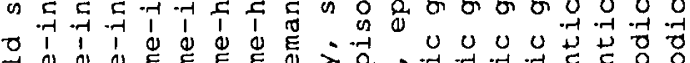

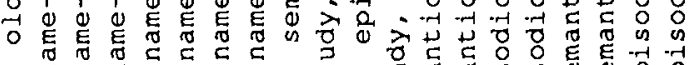

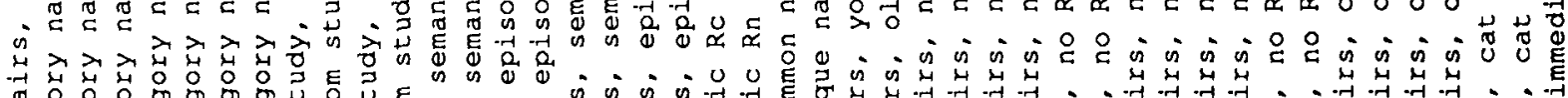

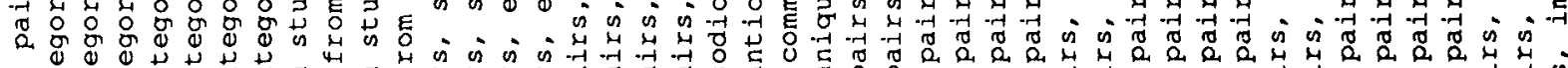
等

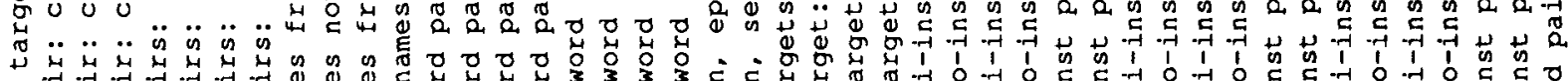

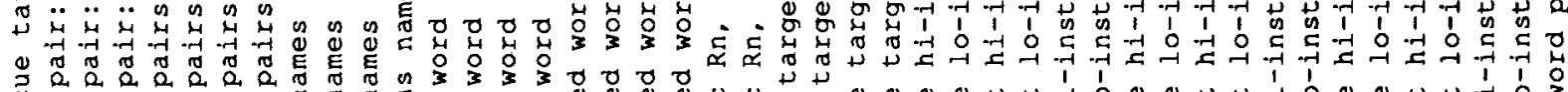

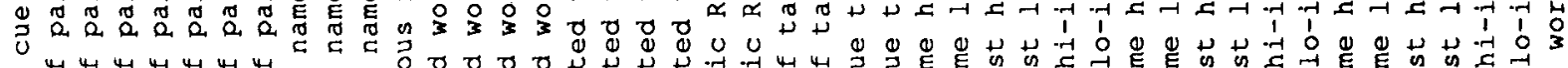

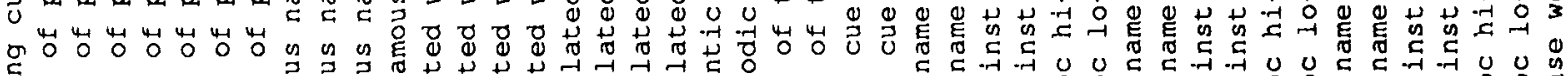

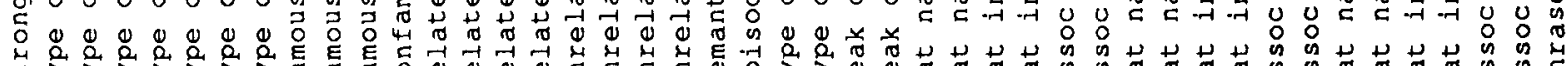

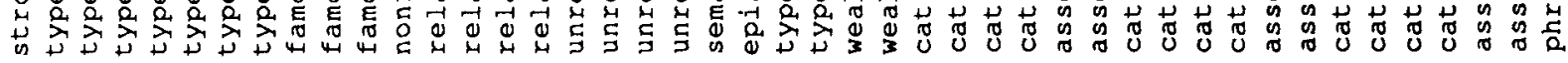
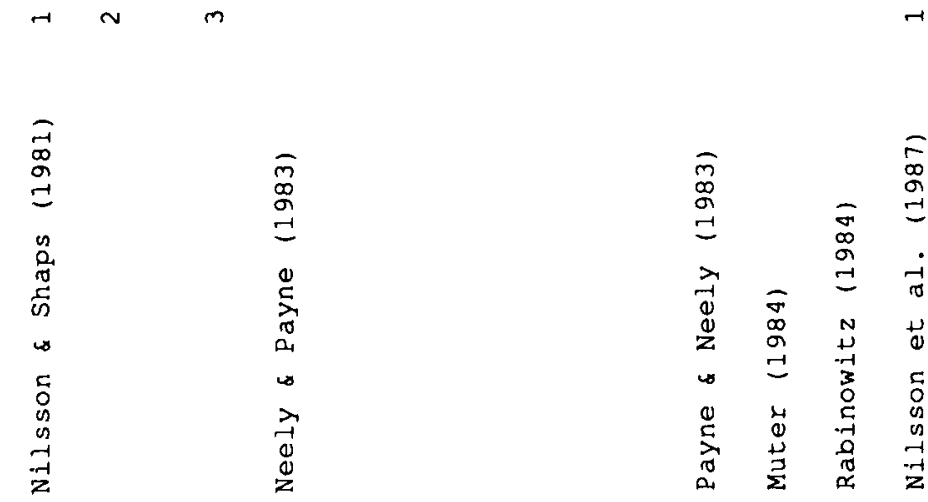

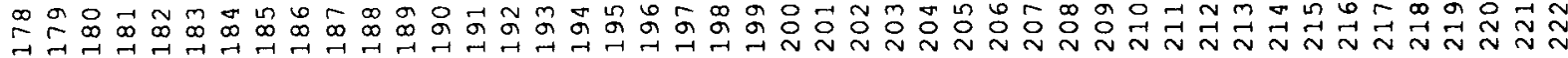




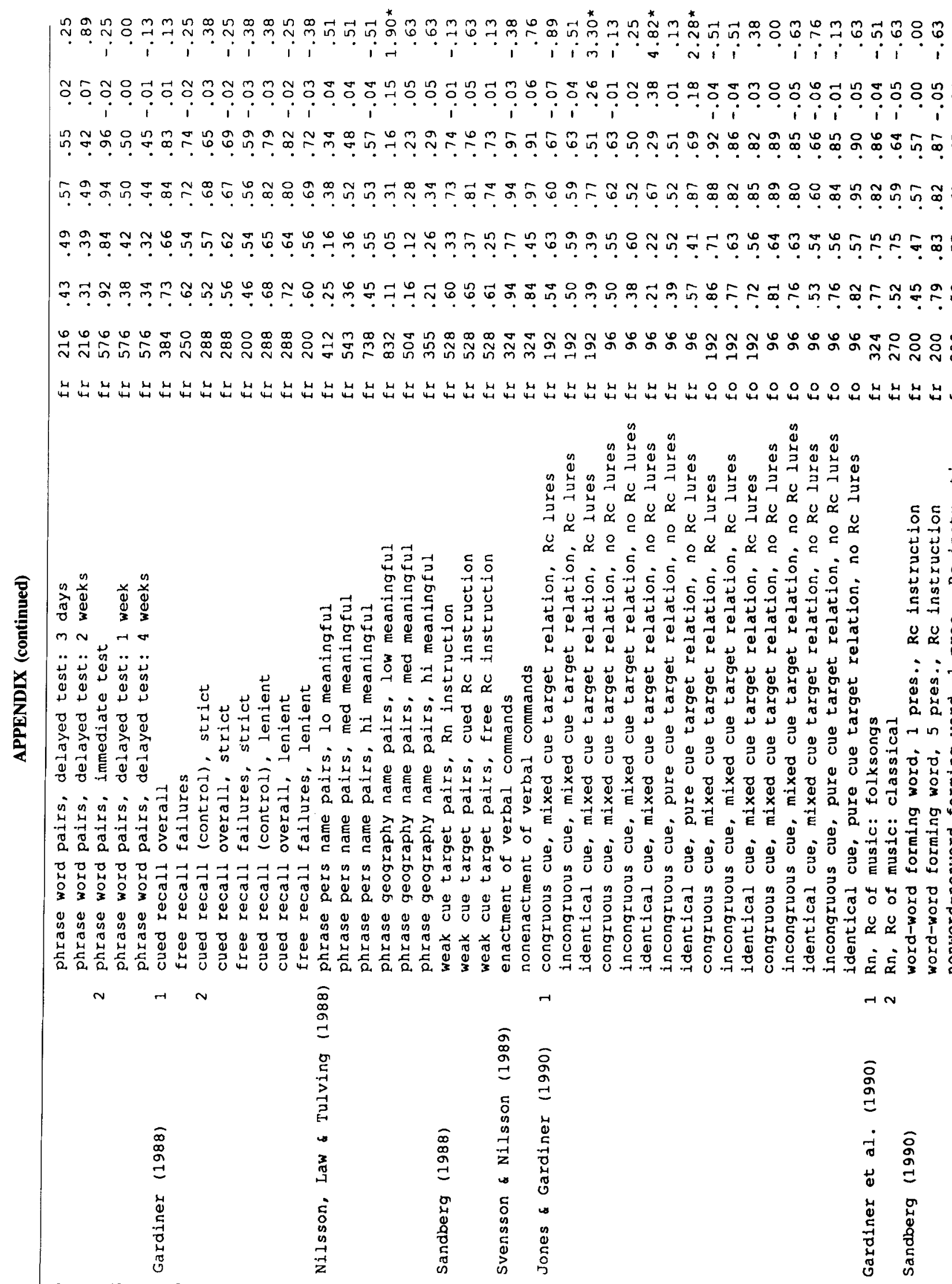

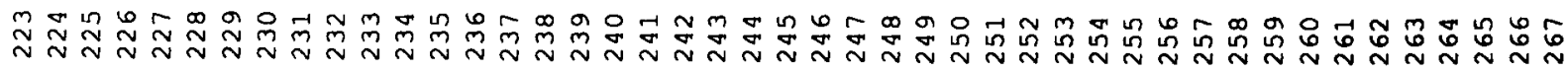




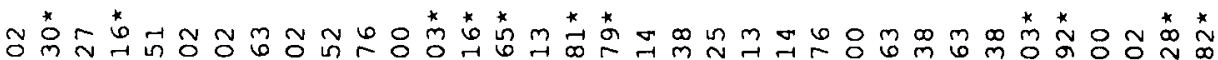

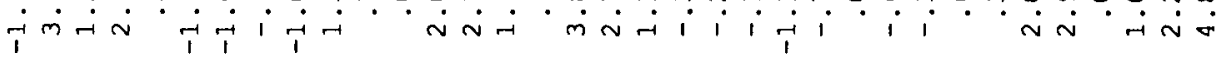

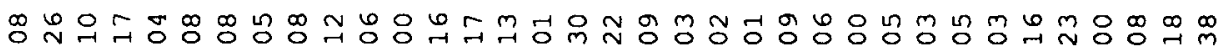

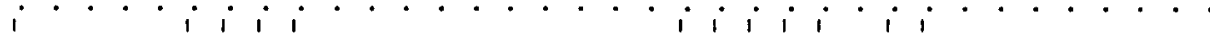

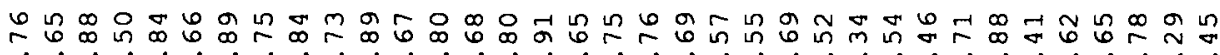
我 ก

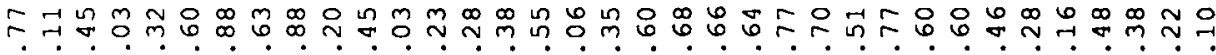

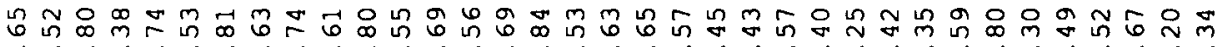

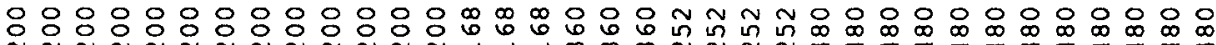

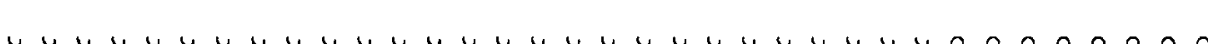

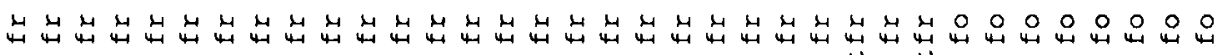

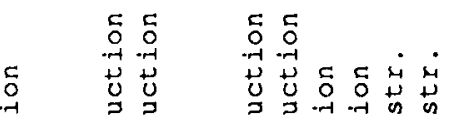

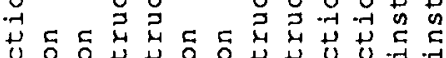
U

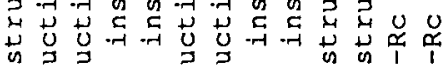

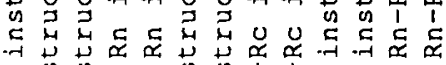

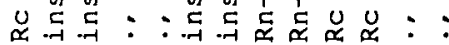
$: 00 \%$

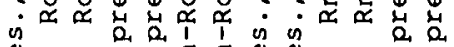

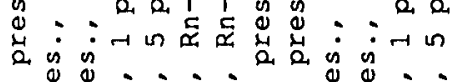

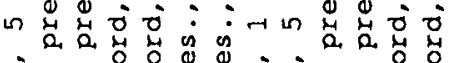

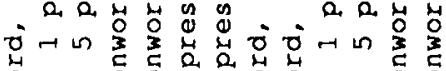

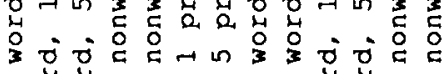
कि

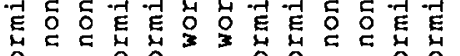

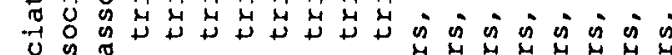

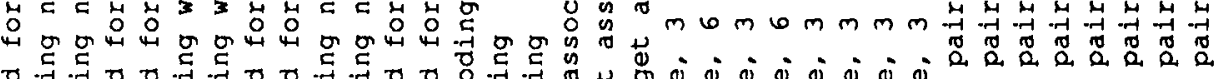

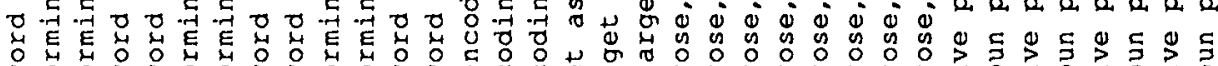

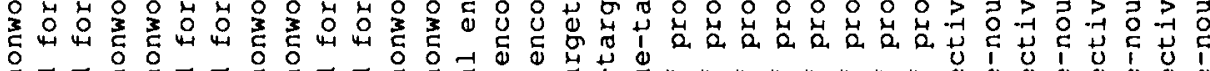
它

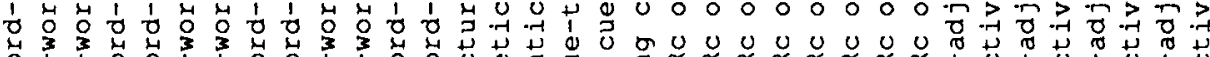

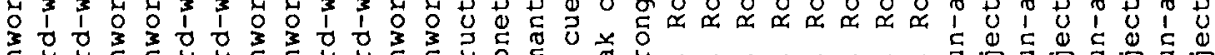

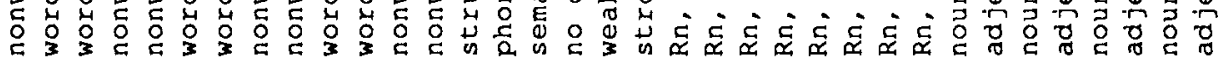

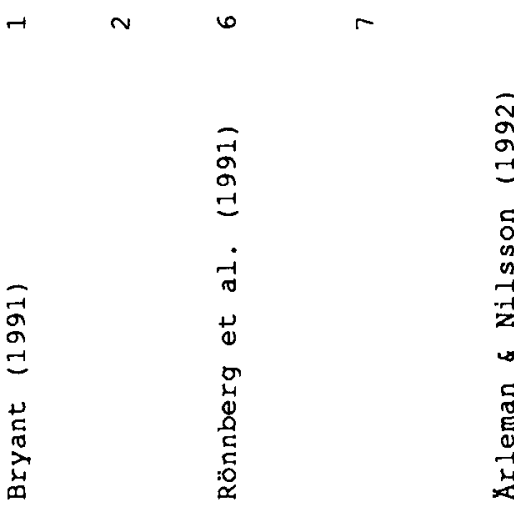

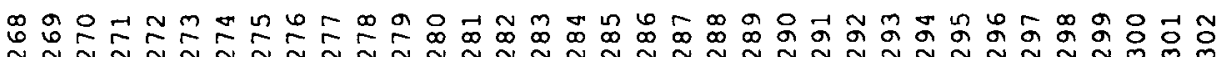

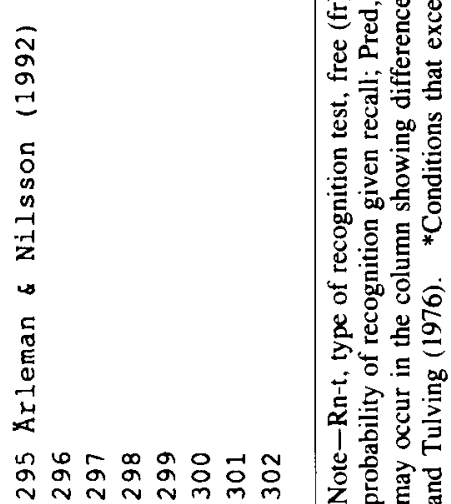

